\title{
Thoracic aortic transection resulting in a type B dissection following blunt trauma
}

\author{
Lance Fogleman, ${ }^{1}$ Terrell Caffery, ${ }^{1}$ Jeffrey Gruner, ${ }^{2}$ Danielle Tatum ${ }^{3}$
}

${ }^{1}$ Emergency Medicine, LSU Health Baton Rouge, Baton Rouge, Louisiana, USA ${ }^{2}$ Trauma Specialist Program, Our Lady of the Lake Regional Medical Center, Baton Rouge, Louisiana, USA

${ }^{3}$ Division of Academic Affairs, Our Lady of the Lake Regional Medical Center, Baton Rouge, Louisiana, USA

Correspondence to

Dr Terrell Caffery,

tcaffe@|suhsc.edu

Accepted 10 November 2017

\section{CrossMark}

To cite: Fogleman $L$, Caffery T, Gruner J, et al. BMJ Case Rep Published Online First: [please include Day Month Year]. doi:10.1136/ bcr-2016-218766

\section{SUMMARY}

A 39-year-old man sustained an acute grade III aortic injury resulting in a type $B$ aortic dissection in the setting of severe traumatic brain injury, cervical spine injury and multiple orthopaedic injuries following a motorcycle crash. The patient underwent an emergent thoracic endovascular aortic repair, complicated by a thoracic pseudoaneurysm rupture and ongoing exsanguination from a persistent type 1 endoleak. Additional stent grafts were required to gain control of the endoleak. The patient ultimately progressed to brain death post procedure in the intensive care unit. This case reviews treatment considerations in the context of a blunt thoracic aortic transection and distal dissection with concomitant polytrauma.

\section{BACKGROUND}

Thoracic aortic transection as a result of deceleration injury is associated with high prehospital mortality. ${ }^{1}$ Less than one in four patients with blunt thoracic aortic injury (BTAI) survive long enough to reach an emergency department (ED), and approximately half of those do expire within 24 hours. ${ }^{23}$ Patients who survive to the ED typically have pseudoaneurysm or incomplete tears requiring emergent repair. The presence of significant extrathoracic injuries complicates clinical management, as optimal care for an associated injury can run counter to optimal care for BTAI. Currently, no evidence-based consensus guidelines or scoring system is available to guide physicians in the care of this challenging patient population. We present a case of thoracic aortic transection resulting in a type $\mathrm{B}$ dissection in the setting of severe traumatic brain injury (TBI) following blunt trauma due to a motor vehicle accident.

\section{CASE PRESENTATION}

A 39-year-old male motorcyclist was travelling at approximately $60 \mathrm{mph}(96 \mathrm{~km} /$ hour $)$ when witnesses reported the motorcycle collided into the driver side of a vehicle that turned in front of the motorcycle. The rider was ejected approximately 50 yards (46 metres), dislodging the helmet and boots. When emergency medical services (EMS) arrived, the patient had a Glasgow Coma Scale (GCS) of 4 and was not conscious, necessitating intubation. The patient was being ventilated via a bag valve mask and was transported by EMS in full spinal immobilisation.
On arrival to the trauma bay, the patient was unconscious with a GCS of 4 and placed on mechanical ventilation. Pupils were equal and reactive but sluggish. The patient had bilateral breath sounds, $2+$ carotid and $1+$ upper extremity pulses, with no palpable femoral pulses. The patient exhibited non-purposeful movements of the upper extremities. Skin was cool and pale with capillary refill greater than $3 \mathrm{~s}$. A $5 \mathrm{~cm}$ abrasion to the top of the head and multiple abrasions of the scrotum and groin were noted. Abdomen was soft and non-distended. No step-offs or crepitus to the thoracic or lumbar spine was noted. There were obvious open fractures to the left wrist, right midshaft femur, right ankle and right fifth toe as well as a deep puncture to the right knee. The open wounds to the lower extremities were noticed to not be bleeding. Following arrival to the ED, the patient exhibited severe hypotension (systolic blood pressure $65 \mathrm{~mm}$ $\mathrm{Hg}$ ) and tachycardia (heart rate $137 \mathrm{bpm}$ ) but then became hypertensive following initiation of resuscitation. Haemoglobin, prothrombin time/partial thromboplastin time and fibrinogen were within normal limits.

\section{INVESTIGATIONS}

A chest X-ray (CXR) showed a widened mediastinum with probable left pulmonary contusion (figure 1). CT scans revealed non-displaced skull fractures, C1-C2 ligamentous injury, subarachnoid haemorrhage, traumatic thoracic aortic transection (figure 2) with pseudoaneurysm formation and dissection extending into the abdominal aorta leaving a slit-like lumen of the aorta (figure 3) but preserving flow to the celiac, superior mesenteric and renal arteries. Additionally, there was a moderate mediastinal haematoma and left hemothorax.

\section{TREATMENT}

An Aspen collar was placed for the C1-C2 ligamentous injury. A left-sided chest tube was placed for hemothorax, with return of approximately $400 \mathrm{cc}$ of blood. Secondary to declining hemodynamics, $4 \mathrm{U}$ each of packed red blood cells and fresh frozen plasma were transfused. Neurosurgery was consulted regarding the traumatic brain injury and cervical spine injury, and no acute intervention was recommended. Extremities were splinted, and open wounds were covered for later orthopaedic intervention. Based on the clinical examination and CXR, vascular surgery was consulted. A CT of 


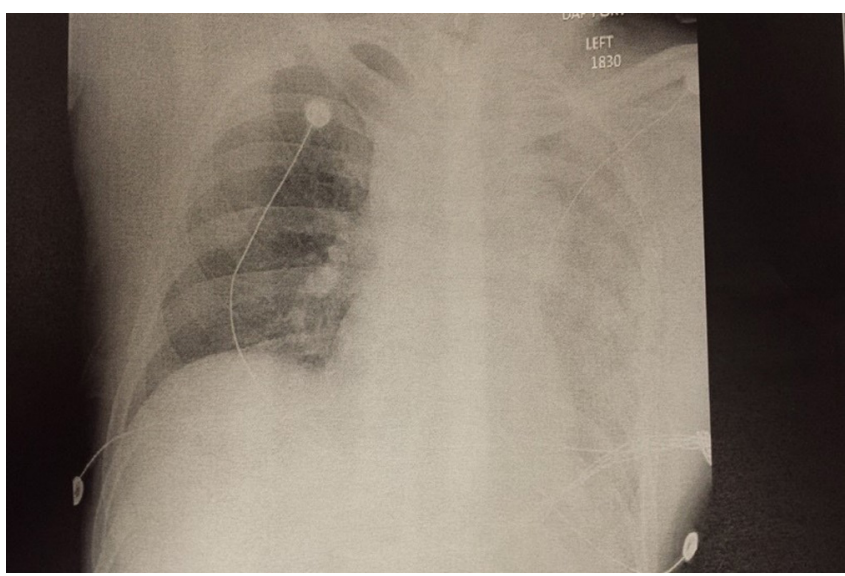

Figure 1 Chest X-ray obtained in trauma bay showing widened mediastinum and left hemothorax versus contusion.

the thorax revealed near complete occlusion of the descending thoracic aorta which started at the ninth thoracic vertebrae and extended distally. It was also noted that the proximal abdominal aorta was slit-like but patent. On reviewing the CT scans, the patient was taken emergently to the hybrid vascular suite for endovascular repair of a large type 1 traumatic aortic transection. Preoperative antibiotics were given, and massive transfusion protocol was implemented due to persistent hypotension and bradycardia. Massive transfusion was delivered in a 1:1:1 ratio of major blood components (plasma, platelets and red blood cells). Access was emergently obtained via the right brachial artery under ultrasound guidance, which was used to perform digital aortic arch angiography. The left femoral artery was then cut down and cannulated, and the main body device of the sheath was placed across the vessel and the graft deployed. The surgical approach was to build up from distal to proximal to cover the transected aorta, which was shown by arch angiogram to be in the proximal descending aorta. Two thoracic aortic stent grafts were placed inferior to superior in a distalto-proximal fashion. The distance from the proximal end of the graft to the lesion was not precisely measured due to the wide area of coverage required by the traumatic leak. The operating assumption was that the site of the traumatic transection was at the aortic isthmus, as this is the most common site of traumatic thoracic aortic injuries. The initial graft placed was a $24 \times 24 \times 100$ (Medtronic) stent graft which was deployed at

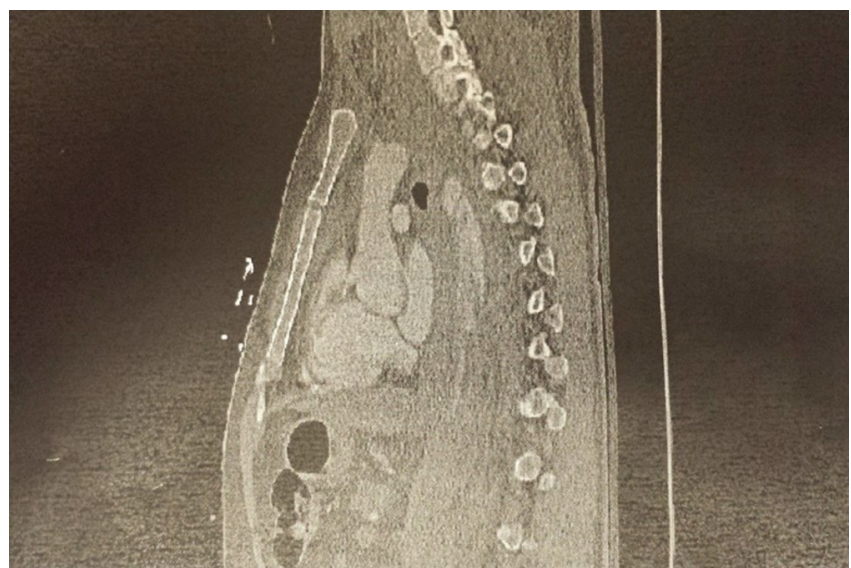

Figure 2 Sagittal CT showing near occlusion of the descending thoracic aorta.

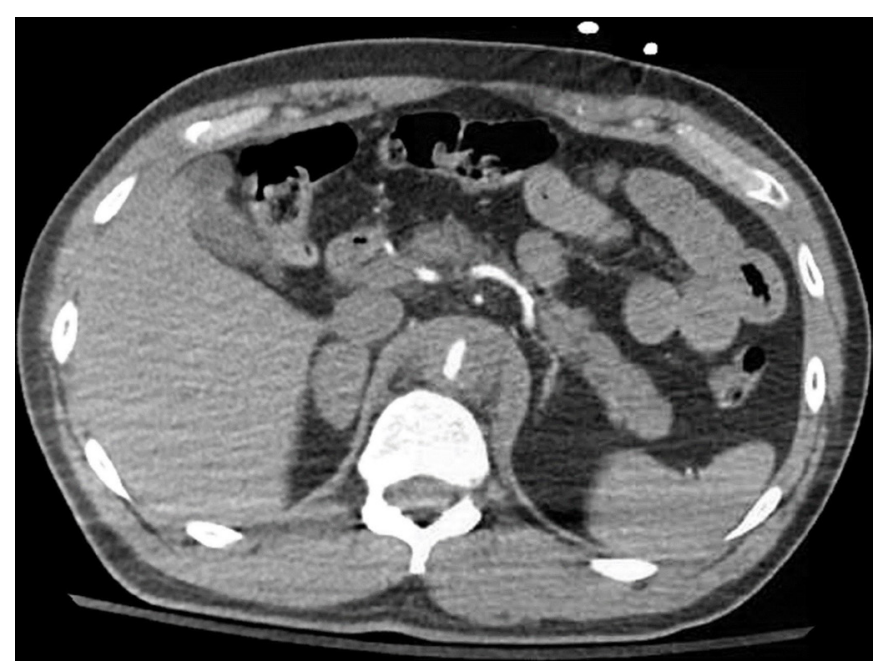

Figure 3 CT scan showing aortic dissection with significant compromise of aortic lumen.

the distal-to-mid descending thoracic aorta. Another arch angiogram was obtained, and the second graft was then advanced over the glidewire under fluoroscopic guidance. This second stent graft, a $26 \times 26 \times 100$ (Medtronic), was deployed just distal to the left subclavian artery to completely cover the transected aorta. This graft was not initially ballooned due to concerns of worsening the traumatic transection. An arch angiogram was again performed with no large endoleak noted, and it was decided to complete the operation. While closing, an acute increase in chest tube output was noted, prompting a repeat angiogram which revealed a persistent type 1 and type 3 endoleak. Massive transfusion protocol was still in place, including autotransfusion of the chest tube output. Maximum doses of vasopressors were required for persistent hypotension. As the patient was a prohibitive candidate for open repair (OR) secondary to concomitant TBI and cervical spine injury, it was then decided to place a third stent graft, size $26 \times 26 \times 100$ (Medtronic), to cover the type 1 and type 3 leak. This graft was deployed even more proximally to completely cover and occlude the left subclavian artery. Additionally, the initial graft was ballooned in order to stunt the type 3 leak, which, in turn, is the likely the event which worsened the type 1 endoleak. The addition of this final graft improved but did not altogether stop the bleeding. Due to the patient's questionable neurological status (GCS 3-4) and several hours of being hypotensive, further intervention was not immediately sought, and the patient was transported postoperatively to the intensive care unit (ICU). In total, the patient received $28 \mathrm{U}$ of packed red blood cells, $24 \mathrm{U}$ of fresh frozen plasma and $30 \mathrm{U}$ of platelets. On examination in the ICU, his pupils were noted to be fixed and dilated. Brain death was later confirmed with a nuclear medicine brain perfusion scan.

\section{OUTCOME AND FOLLOW-UP}

Due to the patient's questionable neurological status and several hours of being hypotensive, further intervention was not immediately sought, and the patient was transported postoperatively to the ICU. On examination in the ICU, his pupils were noted to be fixed and dilated. Brain death was later confirmed with a nuclear medicine brain perfusion scan.

\section{DISCUSSION}

Although it is the second leading cause of death among trauma patients, BTAI accounts for less than $1 \%$ of trauma admissions. ${ }^{4}$ 
Even less frequently observed are traumatic aortic transections resulting in dissections, as trauma rarely causes a classic dissection. More commonly, chest trauma from a high-energy event such as a motor vehicle collision results in aortic rupture or transection..$^{5}$ In the current case, the patient presented with a transection which resulted in a dissection resembling a Stanford type B classification along with a pseudoaneurysm in the setting of traumatic brain injury, a rare combination which made management of the injuries particularly challenging.

Management of BTAI and timing of repair have been the subjects of considerable debate and study in recent years. Treatment may be early (within the first 24 hours) or delayed, interventional (open or endovascular repair) or conservative (medical management). These determinations are largely based on clinical judgement, grading of the aortic injury and the presence of comorbidities and other injuries. ${ }^{6}$

The Eastern Association for the Surgery of Trauma recommends that grade 3 injuries, defined as BTAI with pseudoaneurysm, undergo urgent endovascular repair, ${ }^{7}$ while the Society for Vascular Surgery (SVS) recommends early endovascular repair with medical therapy as a bridge to surgical intervention. ${ }^{8}$ However, in the setting of polytrauma in which a patient may present with major extrathoracic injuries, pharmacological management of blood pressure may obviate this option. BTAI patients frequently present with associated injuries such as TBI, pulmonary contusion and long bone fracture. ${ }^{9}$ The presence of TBI particularly complicates treatment, as maintaining optimal cerebral perfusion pressure may require elevating blood pressure, which can increase the risk of aortic rupture. ${ }^{6}$ The current SVS guidelines for BTAI management are specific to the aortic injury alone and do not consider associated injuries. There is currently no algorithm for optimal BTAI care which incorporates consideration of associated injuries. Development of such an algorithm as well as a consensus grading system is necessary in order to improve overall outcomes in this challenging patient population. Ideally, development of an optimal care algorithm would be generated through a multidisciplinary collaborative effort, allow for consideration of associated injuries and produce an individualised plan of care for the BTAI patient with significant extrathoracic injuries. ${ }^{6}$ Although Thoracic Endovascular Aortic Repair (TEVAR) has emerged as the first choice in definitive BTAI repair, the endovascular approach is not without risks. ${ }^{1011}$ Trauma patients are typically young and, as such, have narrower thoracic aortas than older patients with degenerative aneurysms of the thoracic aorta for which the endografts were specifically designed. Known complications of TEVAR in the young trauma patient population include endoleak, stroke and graft collapse. ${ }^{10} 12$ To account for this risk, the diameter oversizing calculated for the endografts used in the present case was $10 \%$, which is in line with current oversizing standards. ${ }^{13}$ Historically, classic aortic transections which result in type B dissections have historically undergone open repair. ${ }^{14}{ }^{15}$ TEVAR has been reported to be safe and effective with improved outcomes compared with open repair to the $\mathrm{OR},{ }^{8}$ although longterm performance of the endografts in a predominantly younger trauma patient population has not been well assessed..$^{11}$ In this case, the patient's TBI and C-spine ligament injury precluded the ability to use systemic heparinisation for the open repair, a common problematic caveat for the polytrauma patient. ${ }^{6}$ Furthermore, haemodynamic instability and the large size of the aortic lesion necessitated immediate repair. Therefore, the endovascular approach was felt to be the best option.

Because of the high mortality rate for BTAI, few individuals survive to reach an ED. As such, clinicians often have limited or no experience in managing thoracic aortic injury in the presence of polytrauma.

In summary, this case details an unfortunate patient who sustained a blunt thoracic aortic transection and distal dissection with concomitant polytrauma including traumatic brain injury, cervical spine injury and multiple orthopaedic fractures. Treatment options were complicated by a rare combination of aortic injuries in the setting of TBI. It is important to identify associated injuries in BTAI patients, as these injuries may influence or even limit treatment options. An individualised plan of care should be determined by a collaboration of trauma surgeons, vascular surgeons, interventional radiologists and any other key stakeholders necessary to optimally manage the BTAI patient in the setting of polytrauma.

\section{Learning points}

- Prompt recognition of thoracic aortic transection is essential as this injury requires immediate repair.

- Although TEVAR has emerged as the first choice in definitive blunt thoracic aortic injury (BTAI) repair, classic aortic transections which result in type B dissections have historically undergone open repair.

- It is critical to anticipate and identify common concomitant injuries such as TBI, pulmonary contusions and long bone fractures, as these injuries may influence or even limit treatment options.

- Currently, no guidelines exist to guide clinicians in management of BTAI in the setting of major associated injuries.

- In order to improve outcomes, there is a need for a consensus grading system and an optimal treatment algorithm that can be tailored to the specific needs of the BTAI patient who presents with multiple traumatic injuries.

Acknowledgements We would like to acknowledge Mandi Musso for her contribution in reviewing and editing the manuscript.

Contributors LF, TC and JG were involved with patient care and worked together to draft the body of the case report. DT and LF drafted the introduction and discussion. All authors were involved in critically reviewing and revising the manuscript and preparing it for submission.

\section{Competing interests None declared}

Patient consent Detail has been removed from this case description/these case descriptions to ensure anonymity. The editors and reviewers have seen the detailed information available and are satisfied that the information backs up the case the authors are making.

Provenance and peer review Not commissioned; externally peer reviewed. (c) BMJ Publishing Group Ltd (unless otherwise stated in the text of the article) 2017. All rights reserved. No commercial use is permitted unless otherwise expressly granted.

\section{REFERENCES}

1 Turhan H, Topaloglu S, Cagli K, et al. Traumatic type B aortic dissection causing near total occlusion of aortic lumen and diagnosed by transthoracic echocardiography: A case report. J Am Soc Echocardiogr 2004;17:80-2.

2 Fabian TC, Richardson JD, Croce MA, et al. Prospective study of blunt aortic injury: Multicenter Trial of the American Association for the Surgery of Trauma. J Trauma 1997:42:374-80

3 Jamieson WR, Janusz MT, Gudas VM, et al. Traumatic rupture of the thoracic aorta: third decade of experience. Am J Surg 2002;183:571-5.

4 Clancy TV, Gary Maxwell J, Covington DL, et al. A statewide analysis of level I and II trauma centers for patients with major injuries. J Trauma 2001;51:346-51.

5 Smith MD, Cassidy JM, Souther S, et al. Transesophageal echocardiography in the diagnosis of traumatic rupture of the aorta. N Engl J Med 1995;332:356-62.

6 Dubose JJ, Azizzadeh A, Estrera AL, et al. Contemporary management of blunt aortic trauma. J Cardiovasc Surg 2015;56:751-62. 
7 Fox N, Schwartz D, Salazar JH, et al. J Trauma Acute Care Surg 2015;78:136-46.

8 Lee WA, Matsumura JS, Mitchell RS, et al. Endovascular repair of traumatic thoracic aortic injury: clinical practice guidelines of the Society for Vascular Surgery. J Vasc Surg 2011:53:187-92.

9 Teixeira PG, Inaba K, Barmparas G, et al. Blunt thoracic aortic injuries: an autopsy study. J Trauma 2011;70:197-202.

10 Demetriades D, Velmahos GC, Scalea TM, et al. Diagnosis and treatment of blunt thoracic aortic injuries: changing perspectives. J Trauma 2008;64:1415-9.

11 Cannon RM, Trivedi JR, Pagni S, et al. Open repair of blunt thoracic aortic injury remains relevant in the endovascular era. J Am Coll Surg 2012;214:943-9.
12 Xenos ES, Abedi NN, Davenport DL, et al. Meta-analysis of endovascular vs open repair for traumatic descending thoracic aortic rupture. J Vasc Surg 2008:48:1343-51.

13 van Prehn J, Schlösser FJ, Muhs BE, et al. Oversizing of aortic stent grafts for abdominal aneurysm repair: a systematic review of the benefits and risks. Eur J Vasc Endovasc Surg 2009;38:42-53

14 Clouse WD. Endovascular repair of thoracic aortic injury: current thoughts and technical considerations. Semin Intervent Radiol 2010;27:055-67.

15 Karmy-Jones R, Jackson N, Long W, et al. Current management of traumatic rupture of the descending thoracic aorta. Curr Cardiol Rev 2009;5:187-95.

Copyright 2017 BMJ Publishing Group. All rights reserved. For permission to reuse any of this content visit http://group.bmj.com/group/rights-licensing/permissions.

BMJ Case Report Fellows may re-use this article for personal use and teaching without any further permission.

Become a Fellow of BMJ Case Reports today and you can:

- Submit as many cases as you like

- Enjoy fast sympathetic peer review and rapid publication of accepted articles

- Access all the published articles

- Re-use any of the published material for personal use and teaching without further permission

For information on Institutional Fellowships contact consortiasales@bmjgroup.com

Visit casereports.bmj.com for more articles like this and to become a Fellow 